\title{
ÍNDICE DE SUSTENTABILIDADE: UM ESTUDO DE CASO NO ENTORNO DO PARQUE ESTADUAL DO UTINGA
}

Ana Paula Gomes Mendonça -anapaulagomesmendonca03@ gmail.com

Universidade Federal do Pará

Fábio Sergio Lima Brito - fabio.lima.ufpa@gmail.com

Universidade Federal do Pará

Rafaela Caroline Barros Silva - barrosrc15@ gmail.com

Universidade Federal do Pará

Juliana Maia Duarte - duartemaiajuliana@gmail.com

Universidade Federal do Pará

Lindemberg Lima Fernandes- linlimfer@gmail.com

Universidade Federal do Pará 


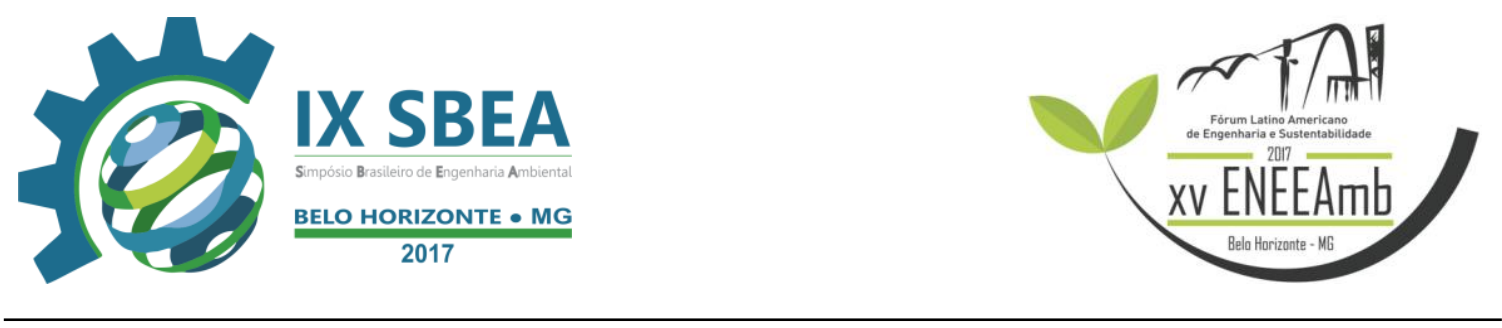

\section{RESUMO}

Detentor de exuberante riqueza natural, com fauna e flora típicas do bioma amazônico, o Parque Estadual Utinga, unidade de proteção integral pertencente a Região Metropolitana de Belém onde abriga os mananciais Bolonha e Água Petra, que são responsáveis pelo abastecimento de água de cerca 2 milhões de habitantes. Apesar da grande importância social e ambiental do parque, nos últimos anos, ele vem sofrendo constantes agressões, consequência da expansão urbana. Por isso, o presente trabalho tem por objetivo avaliar o índice de sustentabilidade no entorno do parque do parque estadual do Utinga. Os métodos de pesquisa compreendem levantamento bibliográfico e aplicação de questionários na área de estudo, bem como, cálculos para medir os índices de sustentabilidade em escalas ambientais, sociais econômicos e institucionais. Os resultados apontaram um índice de sustentabilidade ruim devido várias pressões tais como: muros derrubados, lixo no entorno, queimadas, desmatamentos e invasões. Atesta-se assim que o cenário está em situação de risco socioambiental e isso está afetando a qualidade de vida da população e os recursos naturais.

Palavras-chave: Parque, Índice de Sustentabilidade, Indicadores.

\section{INTRODUÇÃO}

O Parque Estadual do Utinga é uma porção do bioma amazônico na Região Metropolitana de Belém. Seu exuberante 1.393,088 hectares abrigam fauna e flora de floresta ombrófila densa de terra baixa típico desse bioma e passível de extinção.

Caracterizado como Unidade de Conservação (UC) de proteção integral, cuja função é a proteção da natureza e do uso indireto, o que não implica consumo, coleta, dano ou aproveitamento dos recursos naturais ((PLANO DE MANEJO DO PARQUE ESTADUAL DO UTINGA, 2013).

Dentre outras atribuições, o Utinga contribui com o clima, amenizando a temperatura da região; diminui a poluição causada pelo intenso fluxo de veículos; garante o convívio direto do homem com a natureza. 


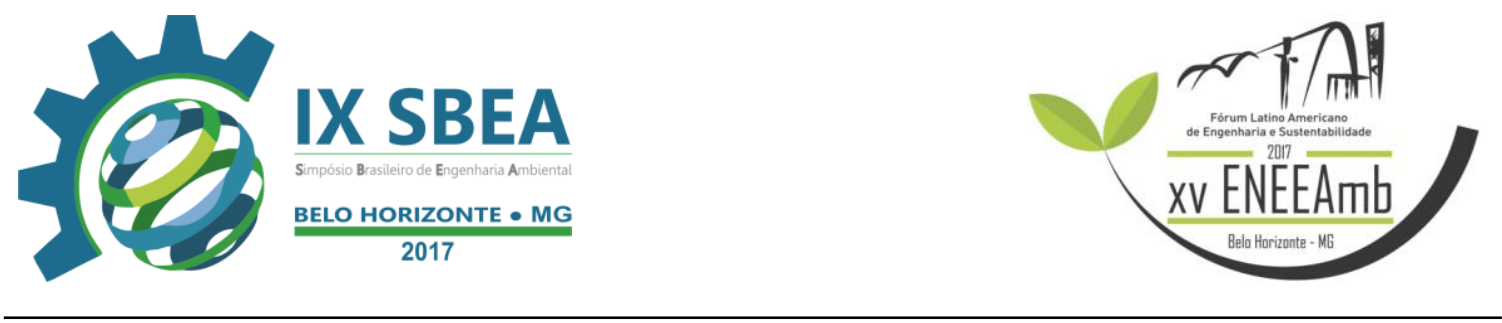

Entretanto nos últimos anos, o parque vem sendo vítima de constantes pressões, em virtude principalmente da expansão urbana nos seus limites, afetando a qualidade de vida da população local e os recursos naturais.

Entre os limites do parque, a região do bairro de Águas Lindas, no município de Belém, demostra grande vulnerabilidade, decorrente dos inúmeros problemas socioambientais que afetam a população de entorno.

Essas pressões vivenciadas no local de estudo fazem surgir à necessidade de avaliação da sua sustentabilidade, através de indicadores, e de que forma afeta a população de entorno.

Primeiramente é preciso entender o conceito de desenvolvimento sustentável. Segundo a ONU, "é o desenvolvimento capaz de suprir as necessidades da geração atual, sem comprometer a capacidade de atender as necessidades das futuras gerações. É o desenvolvimento que não esgota os recursos para o futuro".

Conhecendo o conceito de desenvolvimento sustentável, os indicadores de sustentabilidade mostram a realidade do local, decorrente da ação humana e sua consequência, dando ênfase nos fenômenos que atingem as esferas social, ambiental e econômica. (BELLEN, 2005; KIECHHOFER, 2005; RABELO, 2007).

No rumo ao desenvolvimento sustentável, o Brasil apresenta, segundo o IBGE, 59 indicadores de sustentabilidade, dividido em escopo de quatro dimensões: ambiental, social, econômica e institucional, a fim de averiguar a realidade do país. Os indicadores necessitam ser adaptados a partir da contextualização do local analisado, por isso é preciso escolher minuciosamente os indicadores que vão representar a realidade vigente.

Tendo em vista essas problemáticas que afetam o limite do Parque Estadual do Utinga pertencente ao bairro de Águas Lindas, o presente trabalho pretende diagnosticar e analisar o índice e grau de sustentabilidade por meio das características específicas do local de estudo, que são os indicadores, de forma a classificar a sustentabilidade para a população local.

\section{METODOLOGIA}

A metodologia aplicada no presente estudo baseou-se no método sistêmico, onde se identifica as relações do todo com as partes e das partes entre si, o todo é mais que a 
adição das partes, é a sua soma, das relações entre elas e das relações entre as relações. (Leite Barbosa, 2001). Ou seja, devido ser necessário analisar o objeto de estudo como todo, para classificar sua sustentabilidade, por meio de índices e indicadores, se faz necessário conhecer os sistemas que são os aspectos sociais, ambientais, econômicos e institucionais da área de estudo, uma vez que eles interagem entre si e a organização do todo depende das relações estabelecidas entre eles.

Esse estudo é descritivo, pois para Trivinõs (1987), “os estudos descritivos descrevem os fatos e os fenômenos de uma dada realidade” e segundo Gil (2002, p.42), "[...] as pesquisas descritivas têm como objetivo primordial a descrição das características de determinada população ou fenômeno, e o estabelecimento das relações entre as variáveis".

\subsection{Pesquisa Bibliográfica:}

Estabeleceu-se um levantamento bibliográfico em livros, artigos de periódicos, monografias e matérias disponibilizados pela internet, acerca do tema de desenvolvimento sustentável, com enfoque nos índices de sustentabilidade.

\subsection{Caracterização da Área de Estudo:}

Parque Estadual do Utinga encontra-se na Região Metropolitana de Belém, nos municípios de Belém e Ananindeua, sendo seus limites os bairros Curió-Utinga, Souza, Guanabara, Castanheira, Aurá, Pedreirinha e Águas Lindas. A área do parque abrange 1.393,088 hectares, e está inserido na Área de Proteção Ambiental da Região Metropolitana de Belém.

No seu interior está situado os lagos Bolonha e Água Petra, situados na bacia do Rio Amazonas, no baixo curso do Rio Guamá, seu afluente pela margem esquerda. Esses mananciais são responsáveis pela captação da água para abastecimento público de cerca de 2 milhões de habitantes da Região Metropolitana. $\mathrm{O}$ volume de água dos lagos Bolonha e Água Preta são 1.954.000 e 9.905.000 metros cúbicos, respectivamente.

Especificamente para a análise de sustentabilidade, objetivo desse estudo, destacou-se o entorno imediato do parque, localizado ao leste do seu limite. Trata-se do bairro de Águas Lindas, pertencente ao munícipio de Belém, nordeste do estado do Pará. A extensão territorial do parque na porção referente ao estudo é de $1,7 \mathrm{~km}$, com coordenadas $1^{\circ} 24^{\prime} 43.802^{\prime}$ 'S e $48^{\circ} 23^{\prime} 50.324^{\prime \prime}$ W a $1^{\circ} 23^{\prime \prime} 50.324^{\prime \prime}$ S e $48^{\circ} 23$ '52.894” W, 
e a população de entorno alvo da pesquisa é de 5.846 (PLANO DE MANEJO DO PARQUE ESTADUAL DO UTINGA, 2013).

\subsection{Construção dos Indicadores de Sustentabilidade:}

Segundo Bellen (2005), Rabelo (2007), para construir os indicadores ambientais deve-se seguir as etapas:

- A dimensão ou escopo - ambiental, econômico, cultural, social, institucional;

- O campo de aplicação ou a esfera - global, regional, local;

- Os dados que a ferramenta utiliza - qualitativos e/ou quantitativos, além de apresentar o nível de agregação dos mesmos (indicadores e/ou índices);

- A participação dos diferentes atores sociais na elaboração do sistema top-down (especialistas e pesquisador) ou botton-up (público-alvo).

- A interfase - facilidade em se interpretar os dados para as tomadas de decisões.

\subsection{Coleta de Dados:}

Aplicou-se um pré-questionário com a população local para a avaliação de itens necessários ao estudo e exclusão de outros, de acordo com a realidade observada e assim obtiveram-se os indicadores.

Posteriormente, foi feito a elaboração e aplicação do questionário final afim de apresenta os aspectos relativos à sustentabilidade do objeto de estudo. Foram feitos 60 questionários, cada qual com 14 perguntas.

\subsection{Análise dos Dados:}

Essa é a última etapa do estudo consistiu em realizar os cálculos matemáticos para obtenção do índice de sustentabilidade e posterior avaliação do local. Esse estudo foi desenvolvido a partir da metodologia proposta por Bellen (2005) e Rabelo (2007).

A expressão a seguir demostra o cálculo dos índices individuais de sustentabilidade para cada escopo considerado no estudo:

$$
\mathrm{I}_{\mathrm{W}}=\frac{1}{n} \sum_{j=1}^{n}\left[\frac{\sum_{i=1}^{m} E i j}{\sum_{i=1}^{m} E \max i}\right]
$$




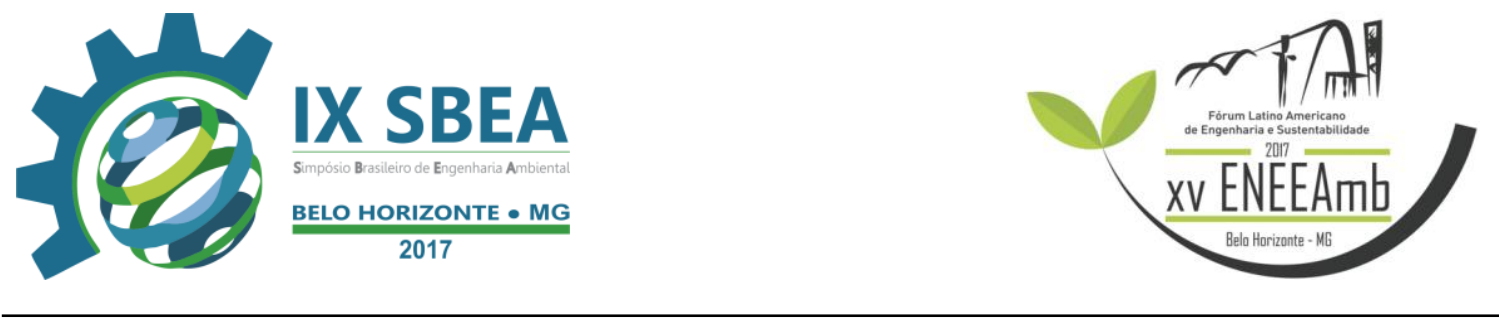

Sendo:

Iw = Índices que comporão o índice de sustentabilidade: econômico, social, ambiental e institucional;

Eij = escore do i-ésimo indicador do Iw obtido no j-ésimo questionário;

Emaxi = escore máximo da i-ésimo indicador do Iw;

$\mathrm{i}=1, \ldots ., \mathrm{m}$, número de indicadores;

$\mathrm{j}=1, \ldots ., \mathrm{n}$, número de questionários aplicados;

$\mathrm{w}=1, \ldots, 4$, número de índices que comporão o índice de sustentabilidade.

$\mathrm{O}$ índice de sustentabilidade incorpora todos os escopos considerados na

pesquisa. A expressão a seguir demostra a mensuração desse índice.

$$
\mathrm{IS}=\frac{1}{k} \sum_{w=1}^{k} I w
$$

Sendo:

IS = índice de sustentabilidade;

$\mathrm{I}_{\mathrm{w}}=$ valor do $\mathrm{w}$-ésimo índice; $\mathrm{w}=1, \ldots, \mathrm{k}$.

Ao final da metodologia deseja-se encontrar o atual estágio de sustentabilidade da área de estudo. O índice de sustentabilidade varia entre 0 e 1 , o valor de 1 significa a melhor condição de sustentabilidade e o 0 significa sustentabilidade não alcançada. A classificação dos estágios de sustentabilidade pode atingir 5 graus, a partir do PUND/ONU (1998), conforme a figura 2.

Tabela 1. Índice de Sustentabilidade

Sustentabilidade excelente (VERDE) $\therefore 1 \leq \mathrm{IS} \leq 0,800$
Sustentabilidade boa (AZUL) $\therefore 0,799 \leq \mathrm{IS} \leq 0,650$
Sustentabilidade média (AMARELO) $\therefore 0,649 \leq \mathrm{IS} \leq 0,500$
Sustentabilidade ruim (ROSA) $\therefore 0,499 \leq \mathrm{IS} \leq 0,300$
Sustentabilidade crítica (VERMELHO) $\therefore 0,299 \leq \mathrm{IS} \leq 0,000$

Fonte: Adaptados de PUND/ONU, 1998

\section{RESULTADOS E DISCUSSÃO}

O diagnóstico do local de estudo mostra através dos registros fotográficos a seguinte realidade, que são algumas das pressões ocorridas no parque. 


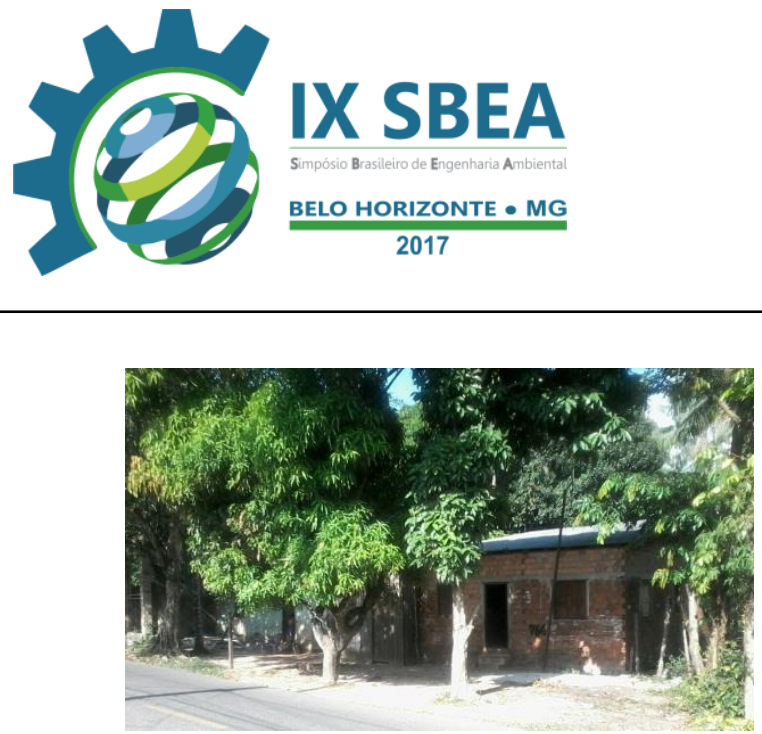

Figura 2 - Moradias irregulares

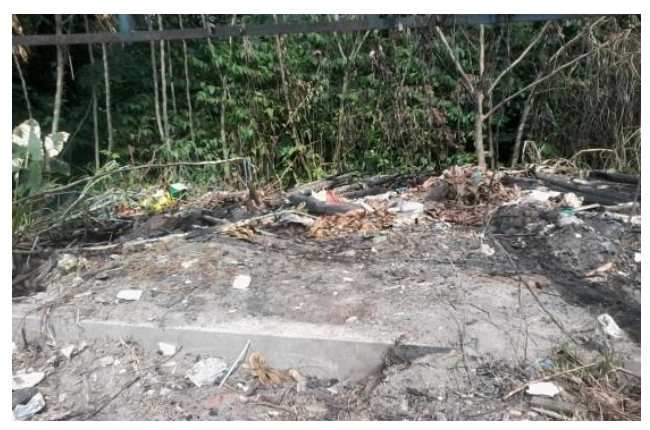

Figura 4 - Queimadas

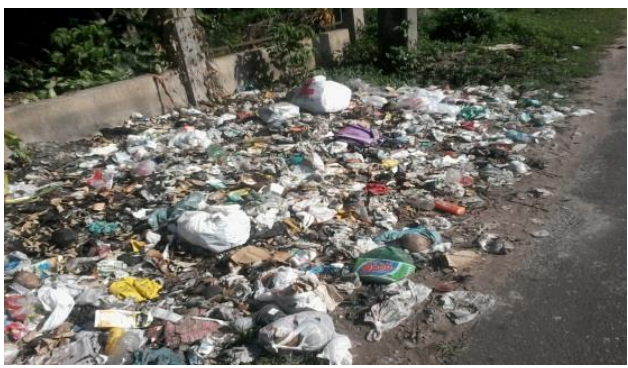

Figura 3 - Lixo entorno

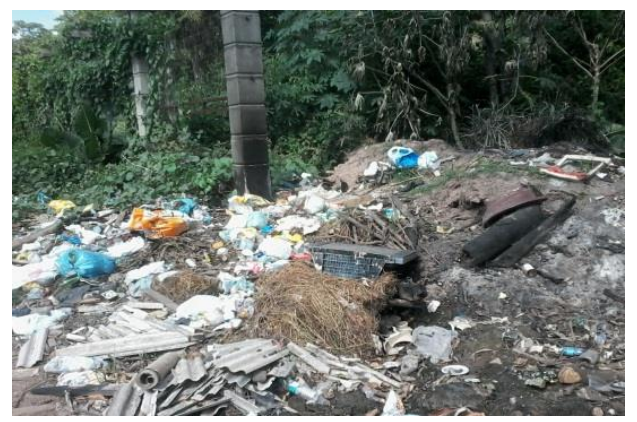

Figura 5 - Lixo/ Muros derrubados

De acordo com os questionários, a população local encontra-se vulnerável a violência e se sente insegura com a área do parque, isso acontece principalmente pela falta de fiscalização no local. A maioria das respostas atestaram haver descarte inadequado de lixo no entorno, por parte dos próprios moradores, mesmo havendo coleta de lixo três vezes por semana no bairro.

Ocorre desmatamento e queimadas, mas são casos pontuais. Todos responderam não haver ação do governo para mudar a realidade da região. Quando perguntados se conhecem alguma proibição de acesso ao parque, a maioria dos respondentes atestou que sim, e entre essas proibições destacaram: "proibido entrar no parque", "acumular lixo", "fazer queimadas", “construir casas", “desmatar" e "caçar".

A medida realizada pelos moradores para melhoria do local é de limpeza para evitar a proliferação de criminosos. A maioria da população respondeu que considera o parque importante para a cidade em que vive, mas está insatisfeita com a realidade que ele se encontra. Quando perguntados quais as melhorias para mudar essa situação, as respostas encontradas no geral foram: "mais fiscalização", "conscientização da 
população", "reestruturação do muro", "projetos para utilização do parque como área de lazer", "políticas públicas", "projetos para garantir emprego e renda da população".

Destaca-se o apelo da população pela melhoria do local, que se encontra em situação de abandono, e grande revolta pela insegurança intensificada pela falta de policiamento na área. Nota-se a mobilização de alguns moradores em organizar uma invasão conjunta ao parque, como forma de chamar atenção da esfera pública para a situação em que o parque se encontra.

Os indicadores escolhidos para descrever a área de entorno ao leste do Parque Estadual do Utinga, de acordo com os referentes escopos foram: Social - Educação, segurança, participação; Ambiental - Saneamento Básico, biodiversidade, legislação; Econômico - Renda; Institucional - Fiscalização.

Para estabelecer os pesos dados para cada indicador de sustentabilidade foi utilizado o método botton-up, onde foi de fundamental importância a participação da população alvo da pesquisa, a partir das entrevistas.

As tabelas a seguir mostram as perguntas e seus respectivos pesos para cada escopo.

Índice Social: Esse índice surge a partir do escopo social e é composto pelos seguintes indicadores: acesso à educação, segurança e participação.

Tabela 2. Índice de Sustentabilidade (IS)/ Índice Social

\begin{tabular}{|c|c|c|}
\hline \multirow[t]{4}{*}{$\begin{array}{l}\text { Escopo } \\
\text { Social }\end{array}$} & $\begin{array}{l}\text { Indicador } \\
\text { Acesso } \\
\text { Educação à }\end{array}$ & $\begin{array}{ll}\text { Aspectos Considerados e Escores atribuídos } \\
\text { Escolaridade: } \\
\text { a) Sem instrução } \\
\text { b) Ensino fundamental incompleto } & 0,5 \\
\text { c) Ensino fundamental completo } & 1 \\
\text { d) Ensino médio incompleto } & 1,5 \\
\text { e) Ensino médio completo } & 2\end{array}$ \\
\hline & Segurança & $\begin{array}{l}\text { A área do parque traz insegurança para a } \\
\text { população do bairro? } \\
\text { a) Sim } \\
\text { b) Não }\end{array}$ \\
\hline & & $\begin{array}{l}\text { Você já foi vítima de algum tipo de violência } \\
\text { nos entornos do parque? } \\
\text { a) Sim } \\
\text { b) Não } \\
\end{array}$ \\
\hline & Participação & Ocorre algum tipo de ação pública (governo) \\
\hline
\end{tabular}




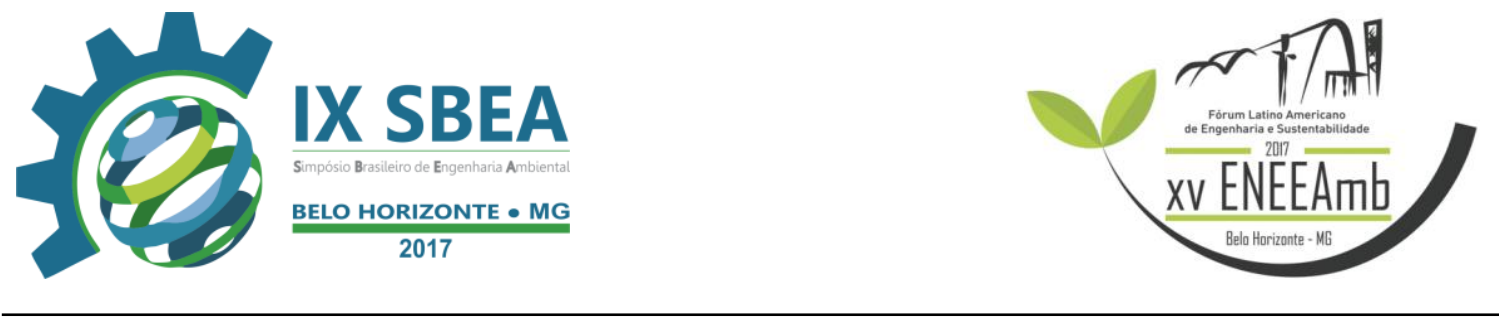

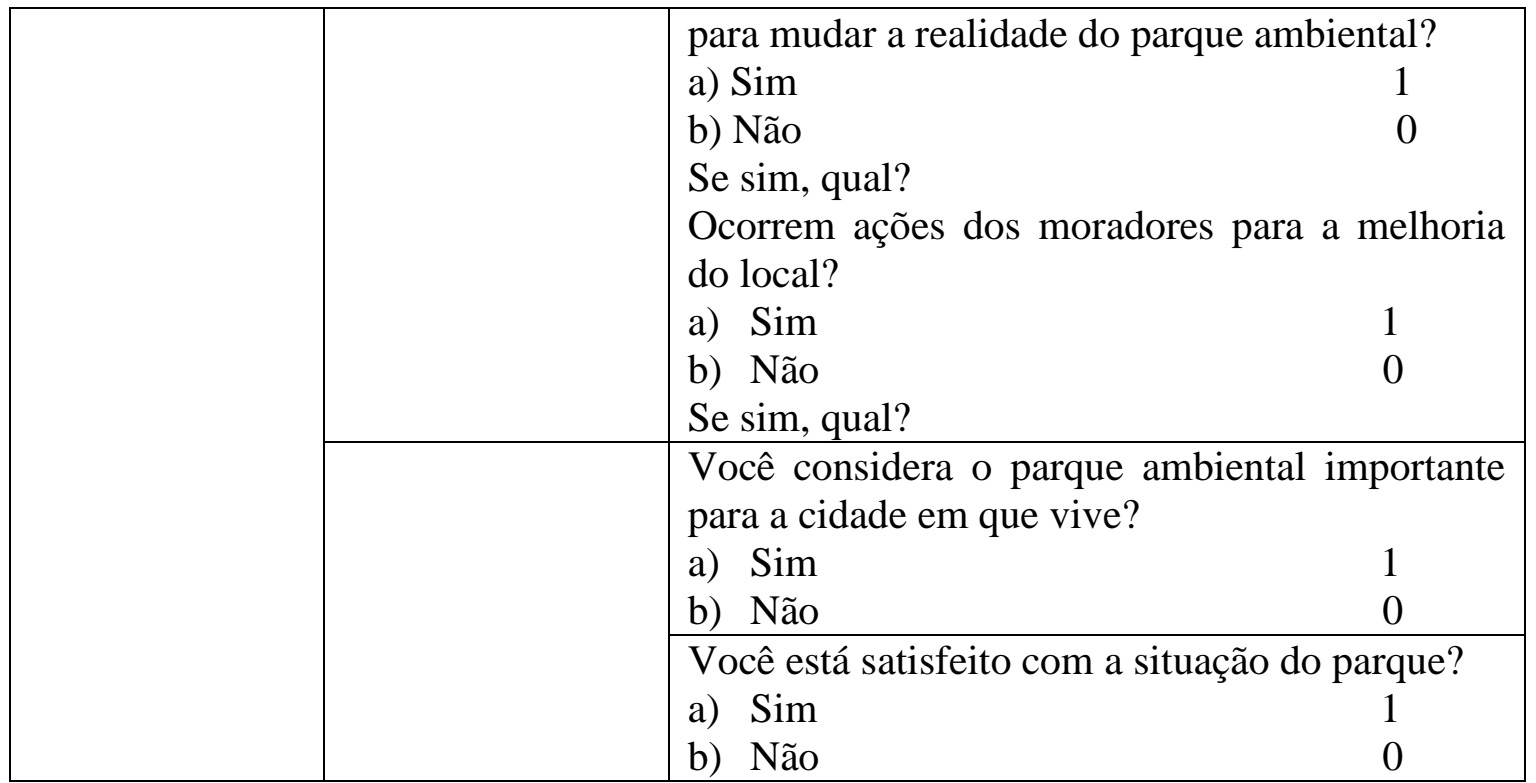

Fonte: Adaptados de Bellen, 2005 \& Rabelo, 2007

Índice Ambiental: Derivado do escopo ambiental, pelos seguintes indicadores: saneamento básico, biodiversidade e legislação.

Tabela 3.Índice de Sustentabilidade (IS)/ Índice Ambiental

\begin{tabular}{|c|c|c|}
\hline \multirow[t]{6}{*}{$\begin{array}{l}\text { Escopo } \\
\text { Ambiental }\end{array}$} & \multirow[t]{3}{*}{$\begin{array}{l}\text { Indicador } \\
\text { Saneamento Básico }\end{array}$} & 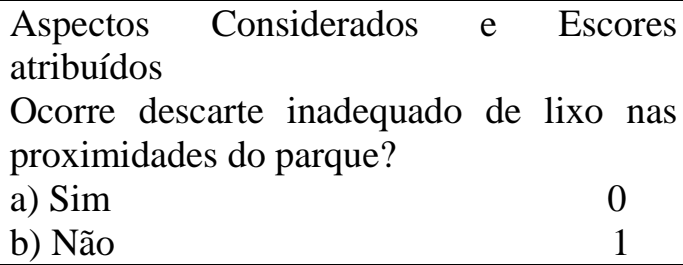 \\
\hline & & $\begin{array}{l}\text { Ocorre coleta de lixo no bairro? } \\
\text { a) Sim } \\
\text { b) Não }\end{array}$ \\
\hline & & \begin{tabular}{ll}
\multicolumn{2}{l}{ Se sim, qual a frequência dessa coleta? } \\
a) 1 vez por semana & 0,5 \\
b) 2 vezes por semana & 1 \\
c) 3 vezes por semana & 1,5
\end{tabular} \\
\hline & \multirow[t]{2}{*}{ Biodiversidade } & $\begin{array}{l}\text { Ocorrem queimadas na região? } \\
\text { a) Sim } \\
\text { b) Não }\end{array}$ \\
\hline & & $\begin{array}{l}\text { Ocorre desmatamento na região? } \\
\text { c) Sim } \\
\text { d) Não }\end{array}$ \\
\hline & Legislação & $\begin{array}{l}\text { Você conhece alguma legislação sobre o } \\
\text { Parque Estadual do Utinga? } \\
\text { c) Sim } \\
\text { d) Não }\end{array}$ \\
\hline
\end{tabular}

Fonte: Adaptados de Bellen, 2005 \& Rabelo, 2007 


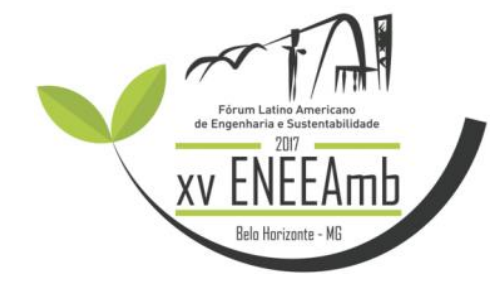

Índice Institucional: Derivado do escopo institucional, pelo seguinte indicador de fiscalização que visa saber se há algo fora das conformidades legais.

Tabela 4.Índice de Sustentabilidade (IS)/ Índice Institucional

\begin{tabular}{|l|l|lr|}
\hline Escopo & Indicador & Aspectos considerados & Escores \\
Institucional & Fiscalização & atribuídos & \\
& & Ocorre fiscalização e/ou & policiamento \\
& & na região? & \\
& & a)Sim & 1 \\
& & b)Não & 0 \\
\hline
\end{tabular}

Fonte: Adaptados de Bellen, 2005 \& Rabelo, 2007

Índice Econômico: Derivado do escopo econômico sendo composto pelo indicador de renda dos moradores do local estudado.

Tabela 5.Índice de Sustentabilidade (IS)/ Índice Econômico

\begin{tabular}{|l|l|lc|}
\hline Escopo & Indicador & Aspectos considerados e Escores atribuídos \\
Econômico & Renda & Renda: & 0 \\
& & a) menos de um salário & 0,5 \\
& & b) até 1,5 & 1,5 \\
\hline
\end{tabular}

Fonte: Adaptados de Bellen, 2005 \& Rabelo, 2007

Os índices de sustentabilidade para cada escopo foram calculados conforme a equação 1 , e o índice de sustentabilidade da área de estudo conforme equação 2 , pode ser observado pela tabela 6 .

Tabela 6. Valores do índice de sustentabilidade

\begin{tabular}{c|c}
\hline Índice & Valor Calculado \\
\hline Índice Social (INS) & 0,439 \\
\hline Índice Ambiental (INA) & 0,563 \\
\hline Índice Institucional (INI) & 0,333 \\
\hline Índice Econômico (INE) & 0,475 \\
\hline Índice de Sustentabilidade (IS) & 0,452 \\
\hline
\end{tabular}

Fonte: Autor, 2017 


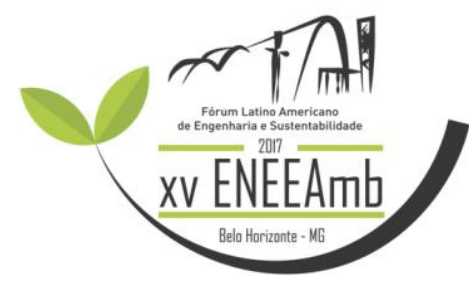

De acordo com a tabela 6 é possível avaliar o grau de sustentabilidade dos valores calculados acima, sendo possível observar na tabela 7 os resultados obtidos pelos escopos. Logo, nota-se que a sustentabilidade do entorno do Parque Estadual do Utinga (águas lindas) é ruim, sendo esta média apenas no índice ambiental.

Tabela 7. Grau de sustentabilidade

\begin{tabular}{c|c|c}
\hline Índice & Valor Calculado & Grau de sustentabilidade \\
\hline Índice Social (INS) & 0,439 & RUIM \\
\hline Índice Ambiental (INA) & 0,563 & MÉDIA \\
\hline Índice Institucional (INI) & 0,333 & RUIM \\
\hline Índice Econômico (INE) & 0,475 & RUIM \\
\hline Índice de Sustentabilidade (IS) & 0,452 & RUIM \\
\hline
\end{tabular}

Fonte: Autor, 2017

\section{CONCLUSÕES}

A fim de averiguar o desenvolvimento sustentável de um local recorre-se ao índice de sustentabilidade através dos indicadores, que expressam a realidade vigente. Sendo o entorno imediato leste do Parque Estadual do Utinga um local que vem sofrendo pressões que afetam o bem-estar social e os recursos naturais, é necessária uma avaliação do desenvolvimento sustentável, para averiguar seu grau de sustentabilidade.

Com base na metodologia proposta por Bellen (2005) e Rabelo (2007) foi estabelecido o grau de sustentabilidade no entorno do parque. Os valores encontrados atestam sustentabilidade ruim no índice econômico, institucional e social, e sustentabilidade média no índice ambiental. O resultado do índice de sustentabilidade geral classificou a sustentabilidade do local como ruim. O que comprova que a área de estudo está em situação de risco e grande vulnerabilidade.

\section{REFERÊNCIAS BIBLIOGRÁFICAS}

BELLEN, Hans M.van. Indicadores de sustentabilidade: uma análise comparativa. Rio de Janeiro: Editora FGV, 2005.

GIL, Antonio Carlos. Como elaborar projetos de pesquisa. 4 ed. São Paulo: Atlas, 2002. 
IBGE - INSTITUTO BRASILEIRO DE GEOGRAFIA E ESTATÍSTICA. Indicadores de desenvolvimento sustentável. 2004. Disponível em: http://www.ibge.gov.br/home/geociencias/recursosnaturais/ids/default.shtm .Acesso em: 10 Jan 2017.

KIECKHÖFER, Adriana Migliorini. Promoção do desenvolvimento integrado e sustentável de municípios. Florianópolis: 2005. 222 f. Tese (doutorado) - Universidade Federal de Santa Catarina (UFSC), Centro Tecnológico (CTC), Programa de PósGraduação em Engenharia de Produção (PPGEP), 2005.

LEITE BARBOSA, Arnoldo P. Metodologia da pesquisa científica. Fortaleza: UECE, 2001.

Plano de Manejo do Parque Estadual do Utinga. Disponível em < http://ideflorbio.pa.gov.br/wpcontent/uploads/2014/10/ResumExcut_Utinga_26out2013. pdf>. Acesso em Mar de 2017.

PNUD / ONU. Atlas do desenvolvimento humano no Brasil. Edição em CD-ROM. Brasília: PNUD, 1988.

RABELO, Laudemira S. Indicadores de sustentabilidade: uma sequência metodológica para a mensuração do progresso ao desenvolvimento sustentável. Tese (mestrado) - Programa Regional de Pós-Graduação em Desenvolvimento e Meio Ambiente (PRODEMA). Universidade Federal do Ceará. Fortaleza, 2007. 170p.

TRIVIÑOS, A. N. S. Introdução à pesquisa em ciências sociais: a pesquisa qualitativa em educação. São Paulo: Atlas, 1987. 175p. 